\title{
Experience of Administering Our First S-STEM Program to Broaden Participation in Computer Science
}

\author{
An-I Andy Wang, David Whalley, Zhenghao Zhang, Gary Tyson \\ Department of Computer Science \\ Florida State University \\ Tallahassee, FL 32306, USA \\ \{awang, whalley, zzhang, tyson\}@cs.fsu.edu
}

\begin{abstract}
This paper documents the findings of our analysis of the implementation of our six-year NSF S-STEM scholarship program. One major finding was that, for underrepresented students to major in computer science, knowing the major existed and understanding the nature of the program were the most important factors. Also, the academic support system and hands-on nature of the major had a significant impact on scholarship recipients' persistence in the major. Evidence demonstrated that scholarship recipients had a $10 \%+$ higher year-to-year persistence rate from their freshmen to sophomore year than that of all computer science students of the same entering classes. For all computer science students, college computer science major GPAs were not strongly correlated with their high school GPAs, financial need, or ACT math scores. This paper also presents lessons learned and resulting recommendations for future new scholarship administrators, as our lessons can likely be applied to other grants that recruit and deal with underrepresented groups.
\end{abstract}

\section{CCS CONCEPTS}

-Social and professional topics-Computer science education

\section{KEYWORDS}

Scholarship grant; underrepresented and minority groups

\section{Introduction}

The number of computing-related jobs has been recently increasing annually at double-digit rates $[1,11,12]$, while the

\footnotetext{
Permission to make digital or hard copies of part or all of this work for personal or classroom use is granted without fee provided that copies are not made or distributed for profit or commercial advantage and that copies bear this notice and the full citation on the first page. Copyrights for components of this work owned by others than ACM must be honored. Abstracting with credit is permitted. To copy otherwise, or republish, to post on servers or to redistribute to lists, requires prior specific permission and/or a fee. Request permissions from Permissions@acm.org.

SIGCSE'20, March, 2020, Portland, OR, USA

(c) 2020 Association of Computing Machinery.

ACM ISBN 978-1-4503-6793-6/20/03...\$15.00

https://doi.org/10.1145/3328778.3366890
}

production of undergraduate students majoring in computer science has been lagging behind. In response, in 2013, the Department of Computer Science at Florida State University (FSU) applied for and received FSU's first NSF S-STEM grant [13] to provide scholarships for talented students with financial need who major in computer science, and to encourage underrepresented students to participate in this major. We had made four prior unsuccessful application attempts to obtain this award, which we documented in [17].

\section{The NSF S-STEM Grant}

The NSF S-STEM grant (program) provides scholarships to promote participants in the general area of science, technology, engineering, and mathematics. To qualify for the scholarship, recipients must be U.S. citizens/permanent residents and must show academic ability and potential as well as financial need, as defined by the Free Application for Federal Student Aid (FAFSA). The maximum grant amount, which we obtained, is $\$ 600,000$ over five years. Only up to $15 \%$ of the fund can be used for administrative purposes and academic support (e.g., faculty salaries and tutors); $85 \%$ needs to be expensed as scholarships.

\subsection{Goals}

Our grant focused on computer science and aimed to increase the participation of underrepresented groups for incoming freshmen in the major. For example, one grant objective was to mitigate the low percentage $(18 \%)$ of female enrollment in computer science $[18,19]$. While causes of this trend, ranging from the nerd stereotype [4] to long hours of socially isolated programming sessions $[2,10]$, are debatable, we explored the enhancement of the academic support system to encourage the retention of females in the program.

Another scholarship focus was to address the trend of underrepresented students' aversion to applying for student loans [9]. Hispanic students, for example, are 15\% less likely to borrow for college than Caucasians. Also, African American and Hispanic students are more likely to work full time, and they are $9 \%$ and $11 \%$, respectively, more likely to leave college without a degree. To avoid the self bias that differs by racial identity, we obtained 
from the financial aid office the eligibility status of S-STEM scholarship applicants on whether they were qualified for subsidized student loan funding (e.g., Stafford), even they did not apply, and awarded them with the matching amount. Note this funding did not prevent the students from taking out the subsidized loans as well.

\subsection{Scholarship Program Components}

The five components of our scholarship program were recruitment, retention, professional development, assessment, and dissemination of results.

2.2.1 Recruitment. Since our department does not have feeder high schools, our recruitment efforts focused on students with undeclared majors who had been admitted to the university, whom we targeted through admissions welcome packets, orientation sessions, student newspaper ads, and our departmental website.

In addition to the financial need and citizenship/residency requirements, our selection criteria comprised three equally weighted components: academic qualifications, personal qualities, and three recommendation letters. To address concerns about top academic performers who would have completed their degrees with or without scholarships [3, 18], we extended our application considerations to include the top 25\% of applicants according to their academic qualifications. The intent was to include students who were not able to reach their full potential due to financial hardships. We also gave special consideration to female applicants and those from other underrepresented groups.

We conducted phone interviews to examine candidates' personal qualities, including motivation, leadership, maturity, persistence, and dedication to obtaining a degree in computer science. Active involvement in extracurricular activities, community service, and work experience were strong indicators of such qualities.

Recommendation letters complemented our interview results when we considered our final selections for the scholarship program.

2.2.2 Retention. As the first line of academic support to enhance retention, dedicated S-STEM tutors provided either oneto-one or one-to-many help sessions. To foster a sense of community, we encouraged participants to enroll in the same set of classes as their cohort peers, to create opportunities to form study groups and a collaborative learning environment to promote retention [8]. We also coordinated with the Computer Science Department at Florida Agricultural and Mechanical University, a historically black university, to provide a dualenrollment program, which helped us to recruit and retain more African American students with fewer African American students enrolled in the FSU Computer Science Program, while providing enough opportunities for them to form project teams and study groups. We further developed interdisciplinary programs with majors with large pools of women and underrepresented students (e.g., computational biology and cyber criminology) to increase the number of women and students from underrepresented groups.

We further collaborated with other on-campus support units, such as the Academic Center of Excellence and the library to provide free tutoring opportunities for general education (noncomputer science major) courses.

2.2.3 Professional Development. We periodically invited Career Center staff to help our students with their resumes and interview skills. We encouraged S-STEM scholars to learn more about their potential career paths by hosting speakers from MIT Lincoln Lab, Microsoft, Intel, Dell, EMC, GE, Harris, UCSB, Omniangle Technologies, New Sci, Captiveyes, Cuttlesoft, Diverse Computing, i2x, Danfoss Turbocor, Louisiana State University, the University of James Madison, and the University of Kansas. We also held workshops on time management and applying for graduate schools and summer internships, to equip students with tools and to obtain recommendation letters and seek employment opportunities.

The scholarship program also offered opportunities for students to develop leadership skills. For example, the scholarship included paid trips for scholars who volunteered to give recruiting talks to high school junior and seniors at school districts in and around their hometowns. Also, the S-STEM tutors and scholars volunteered to create flyers and presentations to promote computer science to K-12 students. A STEM ambassador presented at Lincoln High School, resulting in the recruitment of six students to the computer science major. Another STEM ambassador volunteered to help teens at the Palmer Monroe Teen Center learn the basics of coding and using technologies. Two STEM ambassadors volunteered to tutor mathematics at the Academic Center of Excellence at FSU. In addition, one STEM scholar contributed by volunteering for our local ACM organization.

2.2.4 Assessment. One key metric to measure the success of our S-STEM scholarship program was the year-to-year persistence rate of recipients compared to that of the general student body majoring in computer science from the same entering classes. Another metric was the placement of students in academia and industry. Also, external evaluators interviewed participating students and provided recommendations on how to improve our program (e.g., how to monitor student status more effectively).

2.2.5 Dissemination of Results. This paper clearly shares the findings and lessons learned from our experience of administering this scholarship program. We also documented our four attempts to obtain this NSF S-STEM scholarship award in a paper [17]. As a result, we received requests from 11 universities to use our successful proposal as an example when writing their own applications for the same grant funding. 


\section{Results}

\subsection{High-level Statistics}

Between 2013 and 2018, we recruited 63 students into 3 cohorts (22 in the 2013 cohort, 23 in the 2014 cohort, and 18 in the 2017 cohort). (Each student was awarded an average of $\sim \$ 4,000$ per year. By 2017, we found that we had sufficient scholarship funds remaining to sponsor a new cohort for one year.) Of those, 21 were female, 25 belonged to minority groups (including Hispanics but excluding Asians), and two had disabilities. As of Spring 2018, we graduated 25 students (including 5 females and 13 minority students). Ten went to graduate school, fourteen became software developers at Amazon, Comcast, General Electric, General Motors, Harris, InfoSys, Siemens, Solstice, SynTech, and VR Systems, and one became a research programmer at FSU. From the entering classes of computer science in 2013, 2014, and 2017 , the scholarship enabled the population of female students to be increased by $4.4 \%$ (from $16 \%$ to $20 \%$ ) and of minority students to be increased by $5.5 \%$ (from $27 \%$ to $33 \%$ ).

Table 3.1: Year-to-year persistence rate comparison between the entering classes of 2013 and 2014 computer science students and 2013 and 2014 S-STEM cohorts.

\begin{tabular}{|c|c|c|c|c|c|c|}
\hline & & $\begin{array}{l}2013- \\
2014\end{array}$ & $\begin{array}{l}2014- \\
2015\end{array}$ & $\begin{array}{c}2015- \\
2016\end{array}$ & $\begin{array}{l}2016- \\
2017\end{array}$ & $\begin{array}{l}2017- \\
2018\end{array}$ \\
\hline \multirow{3}{*}{$\begin{array}{l}\text { All } \\
\text { computer } \\
\text { science } \\
\text { students }\end{array}$} & $\begin{array}{c}\text { Entering } \\
\text { class of } \\
2013\end{array}$ & $72 \%$ & $81 \%$ & $89 \%$ & $90 \%$ & $100 \%$ \\
\hline & $\begin{array}{c}\text { Entering } \\
\text { class of } \\
2014\end{array}$ & & $73 \%$ & $77 \%$ & $87 \%$ & $94 \%$ \\
\hline & $\begin{array}{c}\text { Entering } \\
\text { class of } \\
2017\end{array}$ & & & & & $71 \%$ \\
\hline \multirow{3}{*}{$\begin{array}{l}\text { S-STEM } \\
\text { scholars }\end{array}$} & $\begin{array}{c}2013 \\
\text { cohort }\end{array}$ & $86 \%$ & $67 \%$ & $100 \%$ & $100 \%$ & $100 \%$ \\
\hline & $\begin{array}{c}2014 \\
\text { cohort }\end{array}$ & & $84 \%$ & $88 \%$ & $86 \%$ & $100 \%$ \\
\hline & $\begin{array}{c}2017 \\
\text { cohort }\end{array}$ & & & & & $94 \%$ \\
\hline
\end{tabular}

\subsection{Year-to-year Persistence Rates}

The year-to-year persistence rate for the 2013 and 2014 SSTEM cohorts who completed the degree cycle generally improved as the students progressed through the computer science degree program (Table 3.1). The year-to-year persistence rate from freshman to sophomore year was $\sim 85 \%$, whereas the year-to-year persistence rate from junior to senior year was $\sim 93 \%$. All computer science students who entered the program in 2013 and 2014 experienced a year-to-year persistence rate from freshman to sophomore year of $\sim 72 \%$ and a year-to-year persistence rate from junior to senior year of $\sim 88 \%$.

Women in the 2013-2014 S-STEM cohorts had an $81 \%$ average year-to-year persistence rate compared to the $80 \%$ average rate for women from the general student body who entered the computer science program in 2013 and 2014. In addition, minority students in the 2013-2014 S-STEM cohorts had a 90\% average year-to-year persistence rate, whereas the year-to-year persistence rate of all minority students who entered the computer science program between 2013 and 2014 was $85 \%$.

\subsection{Predictors of College Performance}

The 2013 and 2014 S-STEM cohorts had an average high school GPA of 4.07, an average ACT math score of 27, an average college GPA of 3.11, and an average four-year financial need as defined by FAFSA of $\$ 17,597$. All students who entered the computer science program in 2013 and 2014 had an average high school GPA of 3.91, an average ACT math score of 27, an average college GPA of 2.45, and an average four-year financial need as defined by FAFSA of $\$ 9.569$.

Comparing S-STEM and non-S-STEM students, it seemed that financial need may have been linked to college performance. High school GPA and ACT scores were similarly considered as linking to college performance. To prove or disprove these hypothesis, various data were examined. Findings of these analyses reflected that the correlation between financial need and college GPA for the 2013-2014 STEM cohorts and all the computer science students who entered the program in 2013 and 2014 was 0.00 . Also, the correlation between high school GPA and college GPA was below 0.1 for both groups. The correlation between ACT math score and college GPA was 0.22 for the 2013-2014 S-STEM cohorts and 0.03 for the computer science students who entered the program in 2013-2014. Thus, financial need, high school GPA, and ACT math scores were not strong predictors of college performance in computer science. The remaining factors may be attributed to the mentoring support system provided by the S-STEM scholarship program and the filtering mechanism in the S-STEM scholarship application process.

\subsection{Student Exit Survey Results}

Exit surveys of the 2013-2014 S-STEM cohorts identified the motivation to complete the program.

Among the student survey correspondents, $67 \%$ of the surveyed students indicated that the most important factor in their choosing to major in computer science was learning about the existence of the computer science major and associated job opportunities, especially when financially disadvantaged high schools may not have exposed these students to this potential major. Students may also confuse computer science with other majors, such as information technology (IT), scientific computing (SC), computer engineering (CE), and information systems management (MIS). Early clarification of these differences may have reduced the number of students who accidentally chose the wrong major. The remaining 33\% of surveyed students suggested that students should be exposed to computer science major options in high school.

In terms of persistence, $38 \%$ believed that one important factor for their persistence throughout the program was the academic support system, $38 \%$ of the students were attracted to the program 
due to the hands-on nature of computer science, and $25 \%$ persisted because computer science fit their interests (which may reflect that the scholarship application process identified students who had a strong interest in computer science.)

\subsection{Reasons for Leaving the S-STEM Program}

Over the years, students who were unable to continue the scholarship program provided the following reasons: $35 \%$ changed majors (to IT, MIS, business, and biology); $24 \%$ encountered difficulties fulfilling the prerequisites in math (calculus II and discrete mathematics); 18\% had low overall GPAs; $12 \%$ transferred to other universities; $6 \%$ encountered family hardships (e.g., the loss of a family support system); and $6 \%$ became ineligible for financial aid.

We believe that changing majors and failing to fulfill the math prerequisites (59\% of students left) might have been prevented if students were fully informed of the skill sets required and the differences between computer science and similar majors. We might not have lost students with low overall GPAs (18\%) if we had the chance to intervene earlier (see Section 4.9). The loss of the remaining students (24\%) might not have been preventable.

\section{Lessons Learned}

Throughout the scholarship program, we encountered many unanticipated scenarios, which we want to share with our peers.

\subsection{Underestimated Economic Hardship}

During the recruitment process in 2013, we originally used email as the primary form of communication, as $97 \%$ of the population younger than 29 had email access at the time [14]. However, it was disheartening to discover that quite a few in our target population did not have access to email at home, and they had to check email weekly at libraries.

Phone access followed a similar scenario. While $90 \%$ of the population had access to cell phones in 2013 [15], quite a few students only had access to landline phones. Even those with access to cellular phones were difficult to reach during normal business hours due to work and class attendance. Thus, we had to lengthen the recruitment timeline, accommodate our interview schedules, and adjust our expectations for the response to our communications.

In retrospect, we could have budgeted some $\$ 25$ prepaid phones into the scholarship fund, and asked the applicants the need for those phones to ease the initial interview and coordination process.

Therefore, our first lesson learned was not to underestimate the level of economic hardship and resulting slow adoption of communication technologies of potential students.

\subsection{Students Might Not Have Heard about CS}

Based on our experience, while incoming freshmen are familiar with video games, websites, and graphical visual movie effects, most cannot distinguish from among computer science, information technology, scientific computing, computer engineering, and information systems management majors. In particular, students may not know about the skillsets required for each major and their prospective job markets. As a result, we lost many students to the IT department from the 2013 cohort between the sophomore and junior years, since students were not aware of the mathematics prerequisites (e.g., discrete mathematics and calculus II) required to pursue the computer science degree.

This lesson helped us to clarify the nature and requirements of computer science early during the interview process during subsequent recruitment efforts, so that students would not accidentally commit to the wrong major.

\subsection{Single Cohort Enrollment Was Not Realistic}

Our original intent for having cohorts enroll in similar classes was to encourage opportunities to form project teams and study groups. However, the diverse mathematics backgrounds (ranging from college algebra to calculus II) as their highest completion level disrupted the cohort enrollment as different computer courses may have different mathematics prerequisites. Therefore, our original plan for a single cohort enrollment was effectively fragmented, and participants instead were grouped based on mathematics prerequisite courses completed.

One potential way to address this issue would be to recruit scholarship recipients based on mathematics course prerequisites completed (e.g., having completed calculus I). However, this solution may limit the applicant pool to those from school districts offering AP courses. Another alternative is to favor students who have not completed calculus, which could potentially target students from poorer school districts.

\subsection{Fund Distribution Was Not Straightforward}

Originally, we envisioned that the scholarships would be paid directly to the school to offset the tuition in a streamlined fashion, so that students would have one fewer transaction to handle. In reality, we were bewildered by the lack of direct mechanisms to distribute scholarships. Students had to get around the system by registering themselves as vendors, and the disbursement of the first scholarship payment at times did not occur until two months into the semester. As a result, new scholarship recipients had to apply for delayed tuition payment (without penalty) for the first semester to make the ends meet. However, for all remaining semesters, the scholarship disbursement could be completed within a two-week disbursement period. We recommend future adopters work through the university's bursary service to pay their scholarship in advance to avoid the delay in first-payments.

\subsection{Some Students May Game the System}

To prevent students from dropping computer science courses after receiving the scholarship and then changing majors, scholarship disbursement was delayed until after the course drop deadline and after checking that all students were making progress toward completing a computer science degree. However, we found a loophole where double major students could 
claim that they were making progress toward the non-computer science degree while not taking computer science courses for the semester. To close this loophole, we required even double major students to take computer science courses each semester.

Another form of gaming the system by students was pretending to be a freshmen applicant, while holding many community college credit hours, ready to transfer those credits after receiving the scholarship award. Fortunately, we only encountered one such instance, and the student still contributed to the goal of increasing the diversity of the computer science program.

\subsection{Students Might Have Only Short-Term Need}

Two years after the financial crisis in 2011, many students were in dire need of financial assistance to get through college. By 2015, we found a number of students no longer needed the financial support. On one hand, we felt fortunate for those students whose families were no longer struggling. On the other hand, we felt that we may have missed out on financially supporting more students from families with long-term need, and the upward economic mobility they realized through the scholarship may have made a bigger difference. Unfortunately, identifying such circumstances beyond the scope of information provided through the conventional FAFSA application was beyond our means.

\subsection{Limitations of Scholarship}

We envisioned that the award of the S-STEM scholarship would largely alleviate the economic concerns of scholarship recipients during their college years. However, that was not necessarily the reality. A student's struggling parents and siblings may exert pressure for the student to work to support the family. More than once, we had to advise students to separate their personal concerns from their concerns for the welfare of their parents and siblings. We advised students to focus on completing the program, and advised them that they would be able to contribute significantly more to their parents and siblings afterwards.

We also encountered cases where students lost family members and, subsequently their support system in part or whole due to poor neighborhoods and high crime rates in their hometowns. We felt saddened, but yet powerless to change the effects of childhood zip codes on our students' lives [7].

\subsection{Handling Churn of Staff}

Administering this scholarship over six years required the cooperation of many organizations with many levels of staffsponsored research accounting services, coordinators of academic support services, financial aid office, external evaluators, and collaborators. A churn of staff was anticipated. However, when multiple people from multiple organizations are in transition, the handling of these transitions can be painstaking. As one example, an application may be sent to a previous undergraduate academic program specialist, and that position may be vacant for months.
Email inquiries on the FAFSA qualifications of S-STEM scholars each semester may be sent to the previous assistant director of financial aid and not forwarded to the staff members currently handling those responsibilities.

After the first year, we adopted the following protocol. If responses to emails were not received within one business day, a phone call would be made to the contact person. If the phone call was not returned within one business day, we would email and call the supervisor of the contact person. If we failed to contact that supervisor within one day, we would visit the unit in person to see if there were special circumstances that prevented the communication from occurring (e.g., people on vacation/sick leave/maternity leave, internal reorganization). Granted, there were times the offices may were simply overloaded; in those cases, we adjusted our internal deadlines to avoid the busy periods.

Another issue encountered was that one of our five co-PIs left prior to the end of the scholarship program. Fortunately, we had redundancy in our operation, where two PIs per each year were responsible for administering the scholarship program, preventing this staff change from significantly affecting our program operation.

\subsection{Monitoring Students Was Challenging}

One challenge to monitoring S-STEM scholars was identifying students who were in trouble early in the semester. Unfortunately, many courses do not provide enough feedback until after the first major examination, which may be five weeks into the semester.

As for our tutoring system, top students did not need help. Thus, they seldom contacted the dedicated tutor. The bottom students at times did not realize they were in trouble, or were overwhelmed in general, and so they did not contact the tutor. Thus, tutoring was mostly helpful for monitoring students in the middle range. Over the years, we discovered that the most effective way to reach students was to organize homework sessions instead of tutoring sessions. We encouraged students to work on homework assignments together so they would not feel singled out as students in need of help when showing up at the sessions, and the social atmosphere would be more informal.

Another approach we implemented to encourage students to report their status was to disburse scholarship funding in batches. The first batch was large enough to cover tuition, but the remaining amount was distributed in smaller batches (e.g., once on the $6^{\text {th }}$ week, once on the $11^{\text {th }}$ week), only after scholarship recipients turned in their grade report forms, signed by various instructors. This measure was quite effective.

\subsection{The Tricky Year-to-Year Persistence Rate}

Our primary metric to compare the success of our S-STEM scholarship program students with that of all computer science students was the year-to-year persistence rate. It turned out to be trickier to compute than it originally appeared, as students at times needed to skip one or more semesters due to internship, medical withdraw, etc. Thus, when computing the year-to-year persistence rate from a prior year to the current term, and the 
student was not enrolled in the current term, it became ambiguous in terms of whether the student was still in the program. As a result, we had to sometimes revise the numbers gathered in the past when a student returned to the program.

Also, the use of the year-to-year persistence rate may be somewhat misleading, as a $90 \%$ year-to-year persistence rate may sound high, but the compounded effect over four years means that only $73 \%$ of students were able to progress from freshmen to seniors. Another bias factor was that many students may not have declared themselves in the computer science major until the junior year, which may explain the high year-to-year persistence rate between the junior and senior year.

\section{Summary and Conclusion}

We have presented our experience of administering a six-year NSF S-STEM scholarship program. Our high-level findings show that the year-to-year persistence rate improved as students progressed further into the program, and S-STEM scholars had $10+\%$ higher year-to-year persistence rate from freshmen to sophomore year compared to non-S-STEM students in the same entering classes. Our data points showed that financial need, high school GPA, and ACT math scores were not strong predictors of college performance in computer science. Student survey results showed that academic support and the hands-on nature of computer science were the primary factors for student persistence in the program. Awareness of the existence and nature of the computer science major was the most important factor for underrepresented students to choose computer science.

Based on our lessons, we recommend the following for future administrators of S-STEM scholarship programs:

- Anticipate and accommodate students with extreme economic hardship by extending them more time and scheduling flexibility to communicate.

- Clarify the nature of computer science and distinguish computer science from neighboring fields (e.g., IT, MIS) early on.

- Anticipate the cohort forming based on completion of prerequisite courses rather than participation in the scholarship program.

- Identify the scholarship distribution channel and workarounds early to avoid disbursement delays.

- Ensure students are taking computer science courses and making progress each semester, including students with multiple majors.

- Target students with long-term financial need, if possible.

- Mentor students to focus on school and separate their economic concerns from those of their parents and siblings.

- Anticipate churn of staff at various academic units and use redundant communication/coordination channels to carry on operations.

- Use informal atmospheres for mentoring, monitoring, and encouraging community building
- Disburse scholarship funding in batches to ensure that students report their status in a timely manner.

- Be mindful that year-to-year persistence rate numbers may need revision as students skip semesters.

While some of these recommendations may seem obvious for experienced scholarship administrators, we report them in a single document so that future new administers can leverage our experience to avoid some of the unexpected obstacles that present themselves with such scholarship programs.

\section{ACKNOWLEDGMENTS}

We would like to thank anonymous SIGCSE reviewer for their invaluable comments. We also thank Esther Diaguila, Betty Stanton, Alfred Vasta, Richard Rubin, Kimberly Pack, Lauren Higbee, Preston Hamlin, Arturo Valery, Jennifer Yarboro, Michael Mullings, Dustin Flematti, Bryon Greene, Somnath Chatterjee, Rick Wells, Karrie Roberts, Edward Johns, Don Levitan, Jim Clamons, and Carl Owenby for supporting and contributing to this scholarship program. This work is sponsored by NSF DUE1259462. Opinions, findings, and conclusion or recommendations expressed in this document do not necessarily reflect the views of NSF, FSU, or the U.S. government.

\section{REFERENCES}

[1] Joel C. Adams. 2014. Computing Is the Safe STEM Career Choice Today, Communications of the ACM, ACM, New York, NY, USA, https://cacm.acm.org/blogs/blog-cacm/180053-computing-is-the-safe-stemcareer-choice-today/fulltext.

[2] Catherine T. Amelink and Elizabeth G. Creamer. 2010. Gender Differences in Elements of the Undergraduate Experience that Influence Satisfaction with the Engineering Major and the Intent to Pursue Engineering as a Career, fournal of Engineering Education, 99(1):81-92. https://doi.org/10.1002/j.21689830.2010.tb01044.x.

[3] Joe G. Baker and Michael G. Finn. 2008. Can a Merit-Based Scholarship Program Increase Science and Engineering Baccalaureates, Journal for the Education of the Gifted, 31(3):322-337.

[4] Sylvia Beyer, Kristina Rynes, Julie Perrault, Kelly Hay, and Susan Haller. 2003. Gender Differences in Computer Science Students. Proceedings of the $34^{\text {th }}$ Technical Symposium on Computer Science Education (SIGCSE), ACM, New York, NY, USA, 49-53.

[5] Sapna Cheryan, Victoria C. Plaut, Paul G. Davies, and Claude M Steele. 2009 Ambient Belonging: How Stereotypical Cues Impact Gender Participation in Computer Science, Journal of Personality and Social Psychology, 97(6):10451060 .

[6] Naomi C. Chesler and Mark A. Chesler. 2002. Gender-Informed Mentoring Strategies for Women Engineering Scholars: On Establishing a Caring Community. Journal of Engineering Education. 91(1) https://doi.org/10.1002/j.2168-9830.2002.tb00672.x.

[7] Raj Chetty, John N. Friedman, Maggie R. Jones, Sonya R. Porter. 2018. The Opportunity Atlas: Mapping the Childhood Roots of Social Mobility. NBER Working Paper No. 25147, National Bureau of Econmic Research, https://www.opportunityatlas.org/.

[8] Joanne Cohoon. 2005. Just Get Over It or Just Get On with It. Women and Information Technology: Research on Under-Representation, The MIT Press, Cambridge, MA, USA.

[9] Alisa F. Cunningham and Deborah A. Santiago. 2008. Student Aversion to Borrowing: Who Borrows and Who Doesn't, The Institute for Higher Education Policy and Excellencia in Education.

[10] Tim Declue, 1997. Academic Computer Science and Gender: A Naturalistic Study Investigating the Causes of Attrition. Dissertation, Southern Illinois University.

[11] C. Brett Lockard and Michael Wolf. 2010. Occupational Employment Projections to 2020, Monthly Labor Review.

[12] NSF, 2012. Science and Engineering Indicators 2012, NSF, http://www.nsf.gov/statistics/seind12/c2/c2s2.htm\#s2. 
[13] NSF, 2013. NSF Scholarships in Science, Technology, Engineering, and Mathematics (S-STEM), $N S F$, https://www.nsf.gov/funding/pgm_summ.jsp?pims_id=5257.

[14] Andrew Perrin and Maeve Duggan. Americans' Internet Access: 2000-2015, 2015. Pew Research Center https://www.pewinternet.org/2015/06/26/americans-internet-access-20002015.

[15] Pew, 2019. Mobile Fact Sheet, Pew Research Center, 2019. https://www.pewinternet.org/fact-sheet/mobile.

[16] Chris Stephenson, Alison Derbenwick Miller, Christine Alvarado, Lecia Barker, Valerie Barr, Tracy Camp, Carol Frieze, Colleen Lewis, Erin Cannon Mindell, Lee Limbird, Debra Richardson, Mehran Sahami, Elsa Villa, Henry Walker, and Stuart Zweben. 2018. Retention in Computer Science Undergraduate Programs in the U.S. ACM. New York, NY, USA https://www.acm.org/binaries/content/assets/education/retention-in-csundergrad-programs-in-the-us.pdf.
[17] An-I Andy Wang, Gary Tyson, David Whalley, Robert van Engelen, Zhenghao Zhang. 2014. A Journal towards Obtaining Our First NSF S-STEM (Scholarship) Grant. Proceedings of the 2014 AM Special Interest Group on Computer Science Education (SIGCSE) Technical Symposium, ACM, New York, NY, USA.

[18] Donald F. Whallen and Mack C. Shelley, II, 2010. Whallen DF, Shelley MC, Academic Success for STEM and non-STEM Majors, Journal of STEM Education, 11(1,2):45-60.

[19] Stuart Zweben. 2013. Computing Degree and Enrollment Trends. CRA Taulbee Survey, 2013. 